\title{
Quality of life assessment in women after cervicosacropexy with polypropylene mesh for pelvic organ prolapse: a preliminary study
}

\author{
Wojciech Majkusiak, Edyta Horosz, Paweł Tomasik, Aneta Zwierzchowska, Mirosław Wielgoś, Ewa Barcz \\ $1^{\text {st }}$ Department of Obstetrics and Gynecology, Medical University of Warsaw, Poland
}

\section{Abstract}

Aim of the study was to assess the changes in the subjective perception of quality of life in patients who underwent abdominal cervicosacropexy for pelvic organ prolapse.

Material and methods: Forty patients with diagnosed pelvic organ prolapse (Pelvic Organ Prolapse - Quantification [POPQ] stage IV or IIIC) underwent abdominal supracervical hysterectomy and cervicosacropexy. The questionnaire concerning the quality of life was filled in before and 6 months after the surgery.

Results: In all patients, an accurate prolapse correction was achieved. In $42 \%$ of patients, stress urinary incontinence (SUI) was diagnosed prior to surgery, while after the surgery in $38.24 \%(p>0.05)$. In $50 \%$ of women, symptoms of overactive bladder (OAB) occurred pre-surgery. These symptoms were reported by $17.65 \%$ of patients postoperatively $(p<0.05)$. Urinary retention was observed in $32.36 \%$ before and in $2.5 \%$ after the surgery $(p<0.05)$. The average score of the quality of sexual life was 5.75 (SD 2.52, $95 \% \mathrm{Cl}$ : 4.41-7.1) before and increased to 7.93 (SD 1.77, 95\% Cl: 6.9-8.95) after the procedure $(p<0.05)$. The mean score of the overall quality of life in relation to POP before and after the procedure was 2.77 (SD 2.39, 95\% Cl: 1.87-8.64) and 9.03 (SD 1.08, 95\% Cl: 8.66-9.43), respectively $(p<0.001)$.

Conclusions: These results show a highly significant improvement of the quality of life in patients who underwent abdominal cervicosacropexy for POP. The change in quality of their sexual life, reduced OAB and urinary retention rates, as well as improvement of the esthetic self-perception may have contributed to this positive effect.

Key words: abdominal cervicosacropexy, pelvic organ prolapse, stress urinary incontinence.

\section{Introduction}

Pelvic organ prolapse (POP) is a growing clinical problem in gynecology. The most common risk factors for this disorder include multiparity, history of vaginal delivery, older age and obesity [1, 2]. The incidence of POP increases with age, with especially high rates after the menopause, due to tissue atrophy induced by hypoestrogenism [1]. In 1996, the International Continence Society (ICS) published a unified classification of POP (Pelvic Organ Prolapse - Quantification; POP-Q) which enables the clinician to precisely and objectively assess the degree of the prolapse, solely on the basis of clinical examination [3]. Available data show that approximately $46 \%$ of women aged $15-96$ years have experienced some degree of POP [4].

Female genital prolapse is not only an anatomical disorder. It is also associated with functional problems regarding miction, defecation and sexual activity. It may also cause chronic pelvic pain [5, 6]. Consequently, POP may cause significant deterioration of the quality of life resulting in gradual professional, social and familial isolation. Therefore, the goal of surgical treatment of this condition is not only to restore adequate anatomy, but also to improve functionality.

Among various surgical techniques and their modifications, the abdominal sacropexy, described in 1962 by $F$. Lane is characterized by good and durable results [7]. Numerous authors emphasize the long-lasting effect of this surgery with regard to the restoration of normal anatomy. This issue becomes particularly important while considering the results of a cohort study which showed high reoperation rates (reaching 30\%) after surgical treatment of incontinence and genital prolapse [8].

In the literature, the reports concerning the subjective assessment of quality of life of women who underwent abdominal cervicosacropexy are scarce.

The aim of this study was to perform a complex analysis of treatment effects, particularly the subjective assessment of quality of life in women who underwent cervicosacropexy via laparotomy for POP correction.

\section{Material and methods}

The study group comprised 40 patients who were operated for POP in the $1^{\text {st }}$ Department of Obstetrics 
and Gynecology, Medical University of Warsaw, from April 2012 to June 2013. The degree of the prolapse was evaluated using an international unified classification of POP. The study group consisted of women diagnosed with POPQ stage IV and POPQ stage IIIc. They were all scheduled for abdominal cervicosacropexy (supracervical hysterectomy without ovaries and cervicosacropexy with polypropylene mesh). Before the surgery, all patients were interviewed. Information concerning their obstetric history, hormonal status and any previous procedures performed for the prolapse was obtained. All women filled in a questionnaire regarding the subjective evaluation of quality of life before and 6 months after the surgery. It comprised questions about the general quality of life with POP and the quality of sexual life, both rated using a 10-point analogue scale. Moreover, information on the frequency of accompanying conditions, such as stress urinary incontinence $(\mathrm{SUI})$, overactive bladder $(\mathrm{OAB})$, urinary retention (post void residual volume $>100 \mathrm{ml}$, measured using transabdominal ultrasound), defecation disorders and pelvic pain was obtained. Stress urinary incontinence was diagnosed in all cases on the basis of caught test and 1 hour pad test. Overactive bladder was diagnosed on the basis of urinary diary and urodynamic tests. The effect of the operation was evaluated using the POPQ system. When the patient was diag nosed with POPQ stage II or greater, the treatment was considered a failure.

\section{Surgical technique}

Laparotomy via suprapubic transverse incision was performed. In the event of an intact uterus, the supracervical hysterectomy was performed. Subsequently, the parietal peritoneum at the level of promontory was incised and the anterior longitudinal ligament was exposed. The incision was extended to the level of the culde-sac. A polypropylene mesh was then fixed to the cervical stump and the promontory with non-absorbable sutures. The mesh was covered with peritoneum and thus located extraperitoneally. Perioperative antibiotic prophylaxis was administered in all cases.

The effect of procedure was assessed during the control visits in the Urogynecological Outpatient Clinic at 4 weeks, 6 months and 18 months after the surgery.

$T$-test for mean in paired samples and Wilcoxon sign rank test for paired observations were used for statistical analysis.

\section{Results}

The characteristics of the study group are shown in Table I. An accurate correction of the prolapse was achieved in all patients and no recurrence was ob- served in any of the patients during 18 months of follow-up. Among the disorders accompanying the prolapse, statistically significant differences were observed with regard to symptoms of OAB (urgency, pollakiuria and nocturia): $50 \%$ prior vs. $17.65 \%$ after operation, $p=0.016$, as well as urinary retention: $32.36 \%$ before the procedure and $2.5 \%$ post-surgery, $p=0.0067$. In $42 \%$ of patients, SUI occurred pre surgery. After the surgery, SUI was diagnosed in $38.24 \%$ of women. The difference was not statistically significant. De novo SUI occurred in $3(7.3 \%)$ patients. Constipation was reported by $25 \%$ of patients before operation and $27 \%$ post-surgery. Two patients were re-operated due to mechanical ileus: one after 5 months, the other - 10 days post-surgery. In both cases, intraperitoneal adhesions were the cause of the ileus. One patient was re-operated because of hematoma of the rectus abdominis muscle diagnosed in the early post-surgery period. The mean overall subjective assessment of the quality of life in relation to pelvic organ prolapse was 2.77 (SD 2.39, 95\% Cl: 1.878.64), post operation: 9.03 (SD 1.08, 95\% Cl: 8.66-9.43). The difference was highly statistically significant $p<0.001$ (Fig. 1). Fifty-three percent of women were sexually active pre surgery, whereas after the operation $-47 \%$. The average subjective evaluation of the quality of sexual life before surgery was 5.75 (SD 2.52, 95\% Cl: 4.41-7.1), post-surgery: 7.93 (SD 1.77, 95\% Cl: 6.98.95), $p=0.0017$ (Fig. 2).

\section{Discussion}

Pelvic organ prolapse and the accompanying functional disorders are a growing clinical problem of current gynecology. Among various surgical techniques, abdominal cervicosacropexy and colposacropexy are considered one of the most effective techniques, with the effect persisting in $95 \%$ of women for 3 years postsurgery and in $80-90 \%$ for longer than 5 years [9-12]. Several-year observations proved long-term effects of the procedure in $74 \%$ of patients.

A randomized prospective study comparing the results of sacrocolpopexy with the effects of fixation of the vagina to the sacro-spinal ligament (SSLF) showed that

Tab. I. Characteristics of the study group

\begin{tabular}{lc}
\hline Age $($ mean $\pm \mathrm{SD})$ & $60.87 \pm 1.36$ \\
\hline BMI $\left(\mathrm{kg} / \mathrm{m}^{2}\right)$ & $26.75 \pm 0.54$ \\
\hline Parity & $2.06 \pm 0.17$ \\
\hline Patients post menopause $(\%)$ & 83 \\
\hline Hormonal therapy $(\%)$ & 14.3 \\
\hline POPQ stage IIIc $(n / \%)$ & $(26 / 65)$ \\
\hline POPQ stage IV $(n / \%)$ & $(14 / 35)$ \\
\hline
\end{tabular}




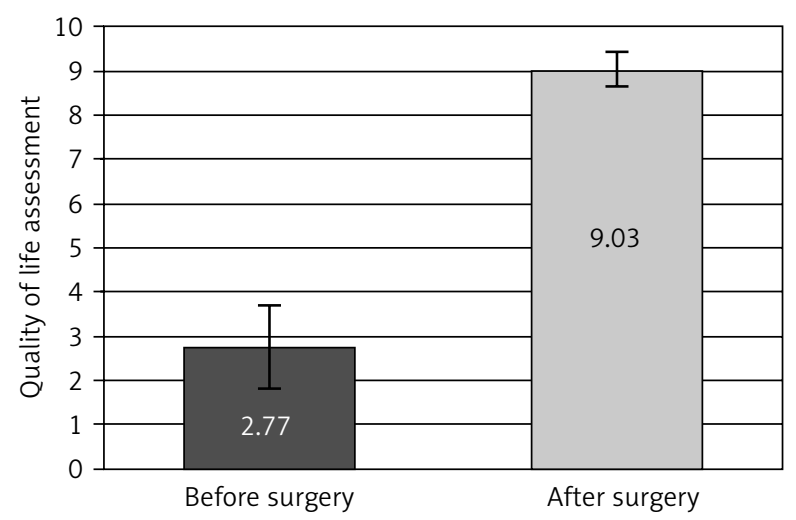

$\mapsto 95 \%$ confidential interval

Fig. 1. Quality of life assessment before and after the surgery

the former operation was more effective. After 5 years, the optimal correction was achieved in $58 \%$ of the women, compared to only $29 \%$ of women who underwent SSLF. Reoperation was necessary in 33\% of women [8].

In an analysis published in 2004, the effectiveness of SSLF was proved to be similar to that of cervicosacropexy ( $76 \%$ vs. $69 \%)$. However, the cumulative rate of recurrence of prolapse of the anterior vaginal wall and vaginal fornix was higher in the SSLF group ( $45 \%$ vs. $13 \%)$. Moreover, SUI occurred more often in these patients (33\% vs. 9\%) [13]. In the current study no POP recurrence was reported.

Stress urinary incontinence occurred with an equal frequency before and after the surgery. Three patients suffered from de novo SUI post-surgery. Lack of reduction in the incidence of SUI as well as the occurrence of de novo SUI was confirmed by other researchers. Reddy et al. observed de novo SUI in 50\% of the operated women [14]. Both Hilger et al. and Joen et al., who analyzed the effects of abdominal sacrocolpopexy, diagnosed this disorder in more than half of the operated patients $[15,16]$. In a study performed by Lefranc et al., $67 \%$ of the 85 analyzed patients suffered from SUI pre surgery. In those women, Burch colposuspension or a sling procedure (Goebbel-Stockel) was performed simultaneously with sacrofixation. Still, the recurrence was observed in $40 \%$ of women [12]. Podratz et al. reported persistence of SUI in 5 out of 6 women in whom sacrofixation was performed simultaneously with retropubic urethropexy [11]. Stress urinary incontinence usually appears during the first three months post operation, when the patient resumes her normal activity. Various factors contribute to this complication, including loss of the support that is normally provided by the uterus and vagina to the urethra, increased urethrovesical angle and surgical hypercorrection of the anterior vaginal wall, particularly in women with low-pressure urethra. The above mentioned studies also show low effectiveness of concurrent prolapse correction and antiincontinence surgery. The opposing forces that result

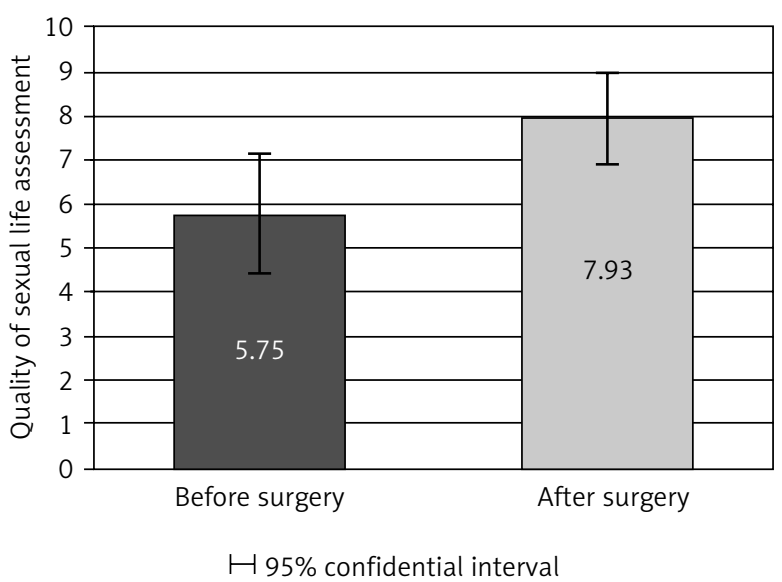

Fig. 2. Quality of sexual life before and after the surgery

from abdominal sacropexy and Burch colposuspension are responsible for non-optimal results of colposuspension [11].

At our unit, we perform a cough stress test with full bladder, with the cervix and/or anterior vaginal wall replaced with a speculum, in all patients scheduled for prolapse correction. Thus, most cases of occult SUI are diagnosed and the affected patients are aware of the high probability of incontinence occurring as a complication of prolapse correction.

All women who suffered from persistent or de novo SUI post-surgery were offered an anti-continence operation or non-surgical treatment for the disorder (depending on the indications). The procedure was performed at least 3 months post prolapse correction. It should be underlined that stress urinary incontinence occurrence after POP repair should be always taken into consideration as it may be a serious clinical problem. In the present study, the authors did not notice the difference of the SUI incidence after the surgery, but it is very much probable that it is connected with a small sample size.

Surgical correction of prolapse was associated with a significant reduction in the rates of urinary retention and symptoms of overactive bladder. This was probably the result of accurate restoration of anatomy. No changes in the functioning of the lower digestive tract were observed. This may be caused by the fact that rectocele is the only one of many factors influencing the pathology of intestines. The occurrence of constipation after cervicosacropexy was more prevalent in women who had suffered from this disorder already before the surgery. This proves the multifactorial etiology of this problem.

Few studies raise the issue of sexual activity of women before and after the prolapse correction. The data concerning sexual life of women who underwent abdominal cervicosacropexy that can be found in the literature are retrospective and often unclear due to a variety of confounding factors, such as age, coexisting 
diseases and medications, as well as hormonal therapy. In the current study, the rate of women who were sexually active pre and post-surgery did not vary significantly. However, among those women who were sexually active, the quality of their sexual life improved. In a research study conducted by Jeon et al., 65\% of women were not sexually active before the surgery and the rate did not change after the prolapse correction, but this resulted mainly from lack of a sexual partner, partner's disease preventing intercourse or lack of sexual drive [16]. Virtanen et al. analyzed the results of a questionnaire filled by 16 sexually active women 3 years post sacrocolpopexy. Forty-three percent of those patients suffered from dyspareunia and 69\% had lowered libido [17]. Baessler and Pilsgard obtained results contrary to the above mentioned studies but in accordance with our findings. Nearly $90 \%$ of women with dyspareunia reported resolution of the symptom after prolapse correction $[18,19]$.

In the literature concerning results of surgical correction of POP, little attention is given to the general assessment of quality of life of patients who undergo these surgeries. In fact, the improvement of the quality of life is the primary goal of prolapse correction. Explaining to the patient the possibility of the occurrence of urinary incontinence after surgical correction of POP and presenting a plan to correct it warrants that the woman will not be disappointed with the effects of the surgery. The reported great improvement in the general assessment of the quality of life after surgical treatment of POP shows the importance of this clinical problem and the role of adequate correction in achieving self-acceptance. Among the variety of methods used for POP correction - from pessary treatment, LeFort colpocleisis offered to selected elderly, not sexually active patients, sacrospinal colpopexy, to laparoscopic techniques, abdominal sacrofixation seems to be effective, eliminating also the functional disorders and, what is particularly significant, ensuring an anatomical effect lasting for many years.

Till now the procedure has been performed in more than one hundred women, therefore the final results of self-evaluation of the patients is still being completed.

\section{Conclusions}

Cervicosacropexy via laparotomy is an effective method to treat pelvic organ prolapse. It is well accepted by patients and, apart from an objective correction of the prolapse, it is also associated with a significant improvement of the quality of life.

\section{Disclosure}

Authors report no conflict of interest.

\section{References}

1. Rechberger T, Miotła P, Futyma K. Czynniki ryzyka defektów dna miednicy u kobiet zakwalifikowanych do operacji rekonstrukcyjnych - polskie badanie wieloośrodkowe. Ginekol Pol 2010; 81: 821-827.

2. Rekomendacje Zespołu Ekspertów Polskiego Towarzystwa Ginekologicznego dotyczące zapobiegania śródporodowym urazom kanału rodnego oraz struktur dna miednicy. Ginekol Pol 2011; 82: 390-394.

3. Bump RC, Mattiasson A, Bø K, et al. The standardization of terminology of female pelvic organ prolapse and pelvic floor dysfunction. Am J Obstet Gynecol 1996; 175: 10-17.

4. MacLennan AH, Taylor AW, Wilson DH, Wilson D. The prevalence of pelvic floor disorders and their relationship to gender, age, parity and mode of delivery. BJOG 2000; 107: 1460-1470.

5. Ellerkman RM, Cundiff GW, Melick CF, et al. Correlation of symptoms with location and severity of pelvic organ prolapsed. Am J Obstet Gynecol 2001; 185: 1332-1339.

6. Olsen AL, Smith VJ, Bergstrom JO, et al. Epidemiology of surgically managed pelvic organ prolapse and urinary incontinence. Obstet Gynecol 1997; 89: 501-506.

7. Lane FE. Repair of posthysterectomy vaginal vault prolapse. Obstet Gynecol 1962; 20: 72-77.

8. Benson JT, Lucente V, McClellan E. Vaginal versus abdominal reconstructive surgery for the treatment of pelvic support defects: a prospective randomized study with long-term outcome evaluation. Am J Obstet Gynecol 1996; 175: 1418-1421; discussion 1421-1422.

9. Snyder TE, Krantz KE. Abdominal-retroperitoneal sacral colpopexy for thecorrection of vaginal prolapse. Obstet Gynecol 1991; 77: 944-949.

10. Timmons MC, Addison WA, Addison SB, Cavenar MG. Abdominal sacral colpopexy in 163 women with posthysterectomy vaginal vault prolapse and enterocele. Evolution of operative techniques. J Reprod Med 1992; 37: 323-327.

11. Podratz KC, Ferguson LK, Hoverman VR, et al. Abdominal sacral colpopexy for posthysterectomy vaginal vault descensus. J Pelvic Surg 1995; 1: 18-23.

12. Lefranc JP, Atallah D, Camatte S, Blondon J. Longterm followup of posthysterectomy vaginal vault prolapse abdominal repair: a report of 85 cases. J Am Coll Surg 2002; 195: 352-358.

13. Maher CF, Qatawneh AM, Dwyer PL, et al. Abdominal sacral colpopexy or vaginal sacrospinous colpopexy for vaginal vault prolapse: a prospective randomized study. Am J Obstet Gynecol 2004; 190: 20-26.

14. Reddy K, Malik TG. Short-term and long-term follow-up of abdominal sacrocolpopexy for vaginal vault prolapse: initial experience in a district general hospital. J Obstet Gynaecol 2002; 22: 532-536.

15. Hilger WS, Poulson M, Norton PA. Long-term results of abdominal sacrocolpopexy. Am J Obstet Gynecol 2003; 189: 1606-1610; discussion 1610-1611.

16. Jeon MJ, Moon YJ, Jung $\mathrm{HJ}$, et al. A long-term treatment outcome of abdominal sacrocolpopexy. Yonsei Med J 2009; 50: 807-813.

17. Virtanen H, Hirvonen T, Mäkinen J, Kiilholma P. Outcome of thirty patients who underwent repair of posthysterectomy prolapse of the vaginal vault with abdominal sacral colpopexy. J Am Coll Surg 1994; 178: 283-287.

18. Baessler K, Schuessler B. Abdominal sacrocolpopexy and anatomy and function of the posterior compartment. Obstet Gynecol 2001; 97 (5 Pt 1): 678-684.

19. Pilsgaard K, Mouritsen L. Follow-up after repair of vaginal vault prolapsed with abdominal colposacropexy. Acta Obstet Gynecol Scand 1999; 78: 66-70. 